\title{
The Isolated Duct of the Rat Cauda Epididymidis as a Model for Isosmotic Transport Studies
}

\author{
P. Y. D. Wong, C. L. Au, and H. K. NGAI \\ Department of Physiology, Faculty of Medicine, \\ University of Hong Kong, Hong Kong
}

\begin{abstract}
Electrolytes and water transport have been studied in the perfused isolated duct of the rat cauda epididymis in vitro. The rates of reabsorption of sodium, chloride and water and of secretion of potassium were found to be comparable to those in the perfused rat cauda epididymidis in vivo. Sodium reabsorption was isotonic and inhibited by the metabolic uncoupler 2,4-dinitrophenol and cooling. Removal of sodium ions from the intraluminal fluid abolished water reabsorption in the isolated duct. When potassium ions were removed from the peritubular medium the secretion of potassium was abolished, but the reabsorption of sodium and water was unaffected. Under this condition, the reabsorption of chloride was enhanced. Removal of calcium ions from the lumen increased the rates of sodium and water reabsorption and potassium secretion by twofold.

Amiloride $\left(10^{-4} \mathrm{M}\right)$ added to the intraluminal fluid had no effect on the electrolyte and water transport in the isolated duct, whereas triaminopyrimidine produced a dose-dependent inhibition of sodium and water reabsorption when added to both sides. Sodium and water reabsorption were found to be inhibited by the application of ouabain $\left(10^{-3} \mathrm{M}\right)$ to the peritubular side and of ethacrynic acid $\left(10^{-4}\right.$ to $\left.10^{-3} \mathrm{M}\right)$ to the luminal side. These results are discussed in the light of the recent concepts of isosmotic transepithelial transport.
\end{abstract}

The rat cauda epididymidis has been shown to reabsorb $\mathrm{NaCl}$ and water in an isotonic proportion, and to secrete $\mathrm{K}^{+}$into the lumen (WoNG and YeunG, 1978). These transport processes are dependent upon the presence of circulating androgens (WoNG and YEUNG, 1977) and to some extent the integrity of the adrenal glands (Au et al., 1978). Electron microscopic study has also provided evidence for water absorption in the isolated rat cauda epididymal duct, for widely dilated intercellular space was seen in an epithelium actively reabsorbing water (WoNG, Y. C. et al., 1978). The mechanism of isosmotic water reabsorption in the rat epididymis seems to have many characteristics similar to that in the mammalian gall bladder (DiAMOND, 1968).

Received for publication July 2, 1979 
Epithelia are generally characterized as being "leaky" or "tight," i.e., as having either low or high transepithelial electrical resistance. The low resistance of the epithelium is attributed to the highly conductive paracellular pathways whose main resistance element is thought to be a "tight junction" (MORENO, 1975). Very recently, triaminopyrimidine (TAP) has been shown to increase the transepithelial resistance in the gall bladder epithelium, by blocking selective sodium channels in the tight junctions (MORENO, 1975). A similar effect of TAP on the intestine and choroid plexus has also been demonstrated.

Another general concept concerning isosmotic transport is that transporting epithelia such as those of the proximal tubule and mammalian gall bladder possess two pumps handling sodium (KLEINZELLER, 1961; WhITTEMBURY, 1968; GieBISCH et al., 1973). One is the classical ATPase-dependent $\mathrm{Na}^{+}-\mathrm{K}^{+}$pump maintaining high $\mathrm{K}^{+}$and low $\mathrm{Na}^{+}$in the cytosol; this pump is inhibited by ouabain or the absence of external $\mathrm{K}^{+}$. The other is a pump handling the extrusion of $\mathrm{NaCl}$ and water in isosmotic proportion across the baso-lateral cell border, responsible probably for transepithelial isosmotic salt and water transport; this pump is inhibited by a diuretic, ethacrynic acid (ETCA).

The aim of the present investigation was to explore in further detail the nature of the isosmotic fluid transfer in the rat epididymis using an isolated preparation of the cauda epididymal duct. Emphasis is laid first on whether the isolated preparation can be used as a model for transport studies, and secondly the mechanism of isosmotic water transport in this preparation along the lines described above by using drugs like amiloride, TAP, ouabain and ETCA. In these experiments, the net fluxes of $\mathrm{Na}^{+}, \mathrm{Cl}^{-}, \mathrm{K}^{+}$and water in the isolated duct have been measured. The transepithelial electrical potential difference across the epithelium has also been recorded.

\section{METHODS}

Isolation of the cauda epididymal duct. Male Sprague-Dawley rats weighing between $350-400 \mathrm{~g}$ were killed by a blow on the head. The eqididymis was exposed through a scrotal incision. The cauda epididymidis was incised from the testes and immersed in cold Krebs bicarbonate solution. The epididymis was then decapsulated and the duct freed with watchmaker forceps and iris scissors. The connective tissue directly surrounding the duct was trimmed away. Care was taken not to rupture the epididymal duct. The dissected length of the cauda epididymal duct was $15.95 \pm 0.26 \mathrm{~cm}$ (mean \pm S.E., $n=60$ ) with a mean external diameter of about $300 \mu \mathrm{m}$. Both the proximal and the distal ends of the duct were tied to polythene cannulae and the duct was immersed in a small bath (volume $10 \mathrm{ml}$ ) which was continuously perfused with Krebs bicarbonate solution prewarmed to $33^{\circ} \mathrm{C}$ and pregassed with $5 \% \mathrm{CO}_{2}$ in $\mathrm{O}_{2}$. The proximal cannula was connected to a Harvard infusion pump and the lumen of the duct was perfused 
Table 1. Composition of solutions (m-mole/liter).

\begin{tabular}{|c|c|c|c|c|c|}
\hline & $\begin{array}{l}\text { Normal } \\
\text { Krebs }\end{array}$ & Na-free & K-free & Ca-free & High $\mathrm{Ca}$ \\
\hline $\mathrm{NaCl}$ & 118 & - & 122.7 & 118 & 106 \\
\hline $\mathrm{KCl}$ & 4.7 & - & - & 4.7 & 4.7 \\
\hline Choline $\mathrm{Cl}$ & - & 143 & - & - & - \\
\hline $\mathrm{CaCl}_{2}$ & 2.56 & 2.56 & 2.56 & - & 10.24 \\
\hline $\mathrm{MgSO}_{4}$ & 1.13 & 1.13 & 1.13 & 1.13 & 1.13 \\
\hline $\mathrm{NaH}_{2} \mathrm{PO}_{4}$ & 1.17 & - & 1.17 & 1.17 & 1.17 \\
\hline $\mathrm{NaHCO}_{3}$ & 25 & - & 25 & 25 & 25 \\
\hline $\mathrm{KHCO}_{3}$ & - & 5.9 & - & - & - \\
\hline EGTA & - & - & - & $2(\mathrm{pH} \mathrm{7.4)}$ & - \\
\hline Glucose & 11.1 & 11.1 & 11.1 & 11.1 & 11.1 \\
\hline $\mathrm{pH}$ & 7.4 & 7.4 & 7.4 & 7.4 & 7.4 \\
\hline Gas* & $\mathrm{O}_{2} / \mathrm{CO}_{2}$ & $\mathrm{O}_{2}$ & $\mathrm{O}_{2} / \mathrm{CO}_{2}$ & $\mathrm{O}_{2} / \mathrm{CO}_{2}$ & $\mathrm{O}_{2} / \mathrm{CO}_{2}$ \\
\hline $\begin{array}{l}\text { Calculated } \\
\text { osmolarity } \\
\text { (m-osmole) }\end{array}$ & 319 & 319 & 319 & 316 & 319 \\
\hline
\end{tabular}

with Krebs bicarbonate solution at a rate of $1.5 \mu 1 / \mathrm{min}$. The cannula at the distal end of the duct was dipped into a sample cup for the collection of perfusate. When the composition of the luminal fluid or the peritubular fluid was varied, the tissue was superfused or luminally perfused with the appropriate solutions whose compositions are shown in Table 1.

Determination of the net fluxes of water and electrolytes. The perfusates were collected into sample cups under oil. Each collection was made over a period of about $40 \mathrm{~min}$ and had a volume of about $60 \mu \mathrm{l}$. The concentrations of $\mathrm{Na}^{+}$ and $\mathrm{K}^{+}$in the perfusate were measured by a flame photometer (Zeiss PF 5) and $\mathrm{Cl}^{-}$was determined by a chloridometer (Buchler-Catlove). The net water flux was measured using ${ }^{3} \mathrm{H}$-inulin as a fluid volume marker. Transepithelial net fluxes of $\mathrm{Na}^{+}, \mathrm{Cl}^{-}$and $\mathrm{K}^{+}$were calculated from the perfusion rate and the inulin and electrolyte concentrations in the perfusion fluid and in the collected perfusate (Wong and Yeung, 1978). Fluxes were expressed in terms of duct length.

Measurement of transepithelial electrical potential difference. In some experiments, perfusion studies were combined with electrical measurement. The ends of the duct (about $5 \mathrm{~cm}$ in length) were tied onto two holding capillaries. One of these (left side in Fig. 1) was constructed as a perfusion system. For this purpose a multi-barrelled catheter was constructed by heating and then pulling polyethylene tubing. The catheter was advanced into the holding capillary and fixed at the tip by a polymerizing adhesive (UHU plus ${ }^{\circledR}$ ). The dead space of the capillary was thus minimized to only a few microliters. By this procedure two single barrels were fitted into the capillary. One of the barrels was for perfusion of the ductal lumen and the other one with its extended into the mid-length of 


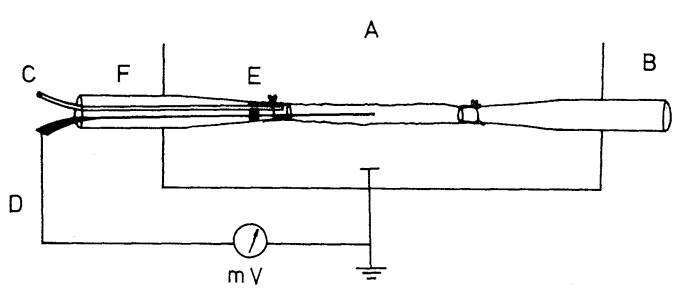

Fig. 1. Measurement of transepithelial electrical potential in the isolated duct of the rat cauda epididymidis. A, tissue bath; B, outflow holding capillary; C, polyethylene barrel for lumen perfusion; $\mathrm{D}$, agar- $\mathrm{KCl}$ electrode and voltage recording circuit; $\mathrm{E}$, sealing cement; F, glass casing.

the duct was filled with agar- $\mathrm{KCl}$ for recording the intraluminal potential. Another agar- $\mathrm{KCl}$ electrode was placed in the peritubular solution and the two electrodes were connected to a digital millivolt meter via calomel half cells. During measurement of the transepithelial electrical potential difference, the perfusate was also collected for estimation of the electrolyte and water fluxes.

Experimental protocol. Each experiment had the following protocol. After the duct had been set up in the perfusion bath, it was perfused with normal Krebs bicarbonate solution for a period of about $15 \mathrm{~min}$ during which no perfusate was collected. The collection was then divided into three consecutive periods. The first period represented the control. In the second period the solutions were changed to the test solutions or the drug was applied into the peritubular medium (or the perfusion fluid when luminal application was desired) and this represented the treatment period. The last 40-min sample was collected after the solutions were restored to normal and denoted as the recovery period.

Drugs. Ouabain (crystalline g-strophanthin) and 2,4-dinitrophenol (2,4DNP) were obtained from Sigma Chemical Co. Amiloride and ETCA were generous gifts from Merck, Sharpe \& Dohme. TAP was synthesized by Dr. Barbara Roth of the Wellcome Research Laboratory, U.S.A.

\section{RESULTS}

\section{Transepithelial electrical potential difference}

When the lumen and the peritubular side were perfused with normal Krebs solution, the transepithelial potential was found to be $0.25 \pm 0.19 \mathrm{mV}$ (mean $\pm \mathrm{S}$.E., $n=5$ ) with the lumen negative with respect to the peritubular medium. These results are not significantly different from zero. In these ducts, the rates of reabsorption of $\mathrm{Na}^{+}, \mathrm{Cl}^{-}$and water and of secretion of $\mathrm{K}^{+}$were found to be $1.73 \pm$ $0.16 \mathrm{n}$-equiv $\cdot \mathrm{cm}^{-1} \cdot \mathrm{min}^{-1}$ (mean \pm S.E.), $1.25 \pm 0.14 \mathrm{n}$-equiv $\cdot \mathrm{cm}^{-1} \cdot \mathrm{min}^{-1}$ (mean \pm S.E.), $12.35 \pm 1.67 \mathrm{nl} \cdot \mathrm{cm}^{-1} \cdot \mathrm{min}^{-1}($ mean \pm S.E. $)$ and $0.166 \pm 0.012 \mathrm{n}$-equiv $\mathrm{cm}^{-1} \cdot \mathrm{min}^{-1}(\operatorname{mean} \pm$ S.E.), respectively. These values were obtained from five 
experiments.

\section{Effects of metabolic inhibitor and temperature}

In five experiments, the effect of 2,4-dinitrophenol, an uncoupler of oxidative phosphorylation was studied. The epididymal duct was first perfused with Krebs bicarbonate solution for $40 \mathrm{~min}$. During this period the rates of net $\mathrm{Na}^{+}, \mathrm{Cl}^{-}$ and water reabsorption and $\mathrm{K}^{+}$secretion were found to be $1.66 \pm 0.24 \mathrm{n}$-equiv $\mathrm{cm}^{-1} \cdot \min ^{-1}$ (mean \pm S.E.), $1.43 \pm 0.11 \mathrm{n}$-equiv $\cdot \mathrm{cm}^{-1} \cdot \min ^{-1}$ (mean \pm S.E.), 10.82 $\pm 1.35 \mathrm{nl} \cdot \mathrm{cm}^{-1} \cdot \mathrm{min}^{-1}$ (mean \pm S.E.) and $0.17 \pm 0.04 \mathrm{n}$-equiv $\cdot \mathrm{cm}^{-1} \cdot \mathrm{min}^{-1}$, (mean \pm S.E.) respectively. In the second period, 2,4 -DNP $\left(10^{-4} \mathrm{M}\right)$ was added to the peritubular solution. The rates were reduced to $0.43 \pm 0.46 \mathrm{n}$-equiv $\cdot \mathrm{cm}^{-1} \cdot \mathrm{min}^{-1}$ (mean \pm S.E.) $(P<0.025)$ for $\mathrm{Na}^{+}$(inhibited by $74 \%$ ), $0.27 \pm 0.48 \mathrm{n}$-equiv $\cdot \mathrm{cm}^{-1}$. $\min ^{-1}\left(\right.$ mean \pm S.E.) for $\mathrm{Cl}^{-}(P<0.025)$ and $0.91 \pm 1.09 \mathrm{nl} \cdot \mathrm{cm}^{-1} \cdot \mathrm{min}^{-1}$ (mean \pm S.E.) $(P<0.001)$ for water reabsorption. The secretion of $\mathrm{K}^{+}$was elevated to $0.34 \pm 0.05 \mathrm{n}$-equiv $\cdot \mathrm{cm}^{-1} \cdot \mathrm{min}^{-1}$ (mean \pm S.E.) $(P<0.025)$.

The effect of temperature was also studied. The cauda epididymal duct was first perfused with Krebs bicarbonate solution at $25^{\circ} \mathrm{C}$. In the second period the temperature was raised to $33^{\circ} \mathrm{C}$, and subsequently to the deep body temperature of $38^{\circ} \mathrm{C}$ during the last period. No net absorption of salt and water was detected at $25^{\circ} \mathrm{C}$. The secretion of $\mathrm{K}^{+}$was much reduced. The rates measured at $38^{\circ} \mathrm{C}$, however, were found not to be significantly different from those measured at the scrotal temperature of $33^{\circ} \mathrm{C}$ (Table 2).

\section{Effects of ions on electrolytes and water transport}

When the isolated ducts were perfused with Krebs bicarbonate solution, the basal rates of $\mathrm{Na}^{+}, \mathrm{Cl}^{-}$and water reabsorption and $\mathrm{K}^{+}$secretion in sixty preparations were $1.81 \pm 0.10 \mathrm{n}$-equiv $\cdot \mathrm{cm}^{-1} \cdot \min ^{-1}$ (mean \pm S.E.), $1.35 \pm 0.10 \mathrm{n}$ equiv $\cdot \mathrm{cm}^{-1} \cdot \min ^{-1}\left(\right.$ mean \pm S.E.), $13.2 \pm 0.66 \mathrm{nl} \cdot \mathrm{cm}^{-1} \cdot \mathrm{min}^{-1}$ (mean \pm S.E.) and $0.18 \pm 0.01 \mathrm{n}$-equiv $\cdot \mathrm{cm}^{-1} \cdot \mathrm{min}^{-1}($ mean \pm S.E.), respectively. These rates were consistent with those measured in the perfused cauda epididymidis in situ (WoNG

Table 2. Effects of temperature.

\begin{tabular}{ccccc}
\hline & $\begin{array}{c}\mathrm{H}_{2} \mathrm{O} \text { reabsorption } \\
\left(\mathrm{nl} \cdot \mathrm{cm}^{-1} \cdot \mathrm{min}^{-1}\right)\end{array}$ & $\begin{array}{c}\mathrm{Na}^{+} \text {reabsorption } \\
\left(\mathrm{n} \text {-equiv } \cdot \mathrm{cm}^{-1} \cdot \mathrm{min}^{-1}\right)\end{array}$ & $\begin{array}{c}\mathrm{Cl}^{-} \text {reabsorption } \\
\left.\text { n-equiv } \cdot \mathrm{cm}^{-1} \cdot \mathrm{min}^{-1}\right)\end{array}$ & $\begin{array}{c}\mathrm{K}^{+} \text {secretion } \\
\left(\text { n-equiv } \cdot \mathrm{cm}^{-1} \cdot \mathrm{min}^{-1}\right)\end{array}$ \\
\hline $25^{\circ} \mathrm{C}$ & $-0.49 \pm 1.49^{*}$ & $-0.25 \pm 0.28^{*}$ & $-0.053 \pm 0.349^{*}$ & $0.102 \pm 0.007^{*}$ \\
$33^{\circ} \mathrm{C}$ & $1(n=5)$ & $(n=5)$ & $(n=5)$ & $(n=5)$ \\
& $12.48 \pm 2.33$ & $1.78 \pm 0.33$ & $1.35 \pm 0.097$ & $0.179 \pm 0.015$ \\
$38^{\circ} \mathrm{C}$ & $13.34 \pm 3.40$ & $(n=5)$ & $(n=5)$ & $(n=5)$ \\
& $(n=5)$ & $1.91 \pm 0.36$ & $1.52 \pm 0.20$ & $0.213 \pm 0.028$ \\
& $(n=5)$ & $(n=5)$ & $(n=5)$
\end{tabular}

Each value shows the mean \pm S.E. The number of observations is shown in parentheses. The values at $25^{\circ} \mathrm{C}$ and $38^{\circ} \mathrm{C}$ were compared to those at $33^{\circ} \mathrm{C}$. A negative value in the water, sodium or chloride reabsorption indicates a net secretion.

* $P<0.005$. 


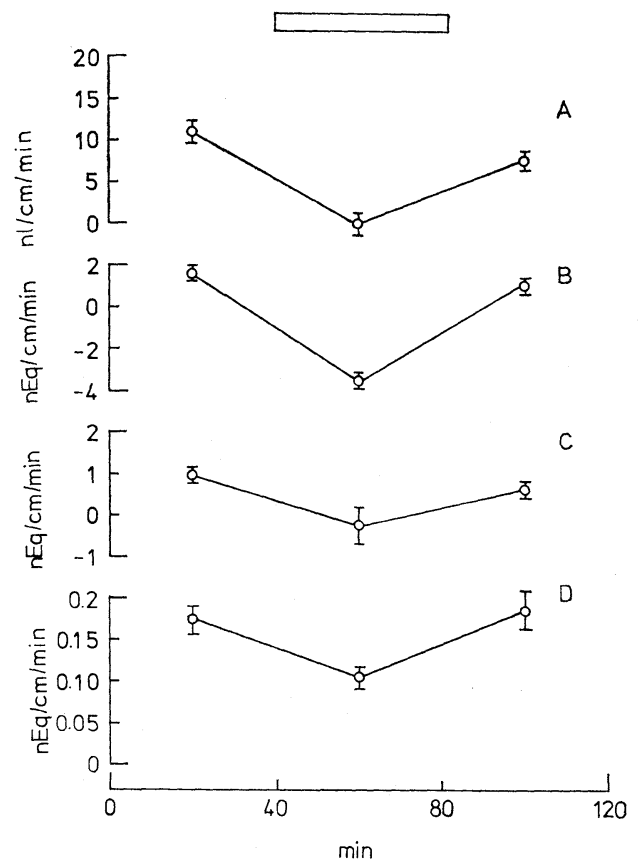

Fig. 2. The effect of intraluminal $\mathrm{Na}^{+}$ions removal on the rate of (A) net water reabsorption, (B) net $\mathrm{Na}^{+}$reabsorption, (C) net $\mathrm{Cl}^{-}$reabsorption and (D) net $\mathrm{K}^{+}$secretion by the isolated duct of the rat cauda epididymidis. Both sides of the epithelium were perfused by a $\mathrm{Na}^{+}$-free solution for $40 \mathrm{~min}$ as indicated. Each point shows the mean \pm S.E. with the number of observations shown in parentheses. The water, $\mathrm{Na}^{+}, \mathrm{Cl}^{-}$and $\mathrm{K}^{+}$ values were obtained from the same samples from six ducts.

and YEUNG, 1978) and indicated an isosmotic water reabsorption in the isolated duct. When $\mathrm{Na}^{+}$was substituted for by choline, reabsorption of water was abolished and the secretion of $\mathrm{K}^{+}$was markedly reduced (Fig. 2). The effect was readily reversible upon restoration of $\mathrm{Na}^{+}$to the perfusion solution.

The effect of removal of $\mathrm{K}^{+}$from the peritubular medium is shown in Fig. 3 . When $\mathrm{K}^{+}$was removed from the bathing medium, the secretion of $\mathrm{K}^{+}$into the lumen was completely abolished $(P<0.05)$. $\mathrm{Na}^{+}$and water reabsorption were little affected. The reabsorption of $\mathrm{Cl}^{-}$was, however, enhanced by the absence of peritubular $\mathrm{K}^{+}$although the difference is not statistically significant. During the recovery period when $\mathrm{K}^{+}$was restored to the peritubular fluid, $\mathrm{K}^{+}$secretion resumed and $\mathrm{Cl}^{-}$reabsorption returned to the normal rate.

The effect of changing the intraluminal $\mathrm{Ca}^{2+}$ concentration on the transport of electrolytes and water is shown in Table 3. When the lumen of the isolated duct of the rat cauda epididymidis was perfused with a $\mathrm{Ca}^{2+}$-free Ringer solution containing EGTA ( $2 \mathrm{~mm}$ ), the sodium and water reabsorption rates were increased 


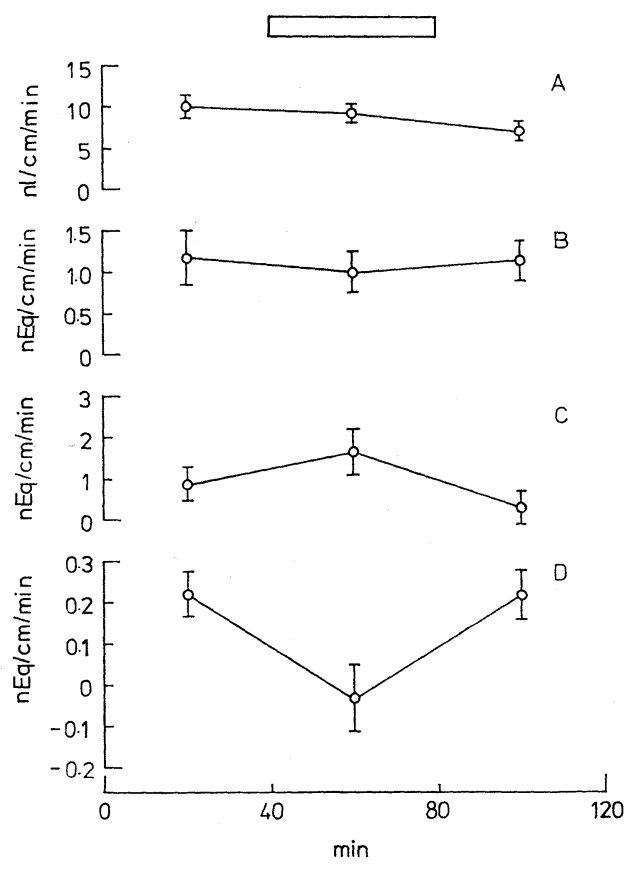

Fig. 3. The effect of peritubular $\mathrm{K}^{+}$ion removal on the rate of (A) net water reabsorption, (B) net $\mathrm{Na}^{+}$reabsorption, (C) net $\mathrm{Cl}^{-}$reabsorption and (D) net $\mathrm{K}^{+}$secretion by the isolated duct of the rat cauda epididymidis. The peritubular side of the duct was perfused with a $\mathrm{K}^{+}$-free solution for $40 \mathrm{~min}$ as indicated. Each point shows the mean \pm S.E. with the number of observations shown in parentheses. The water, $\mathrm{Na}^{+}, \mathrm{Cl}^{-}$and $\mathrm{K}^{+}$ values were obtained from the same samples from six ducts.

by twofold. The secretion rate of $\mathrm{K}^{+}$was also enhanced. These effects were completely reversible upon perfusion of the duct lumen with a solution containing a normal concentration of $\mathrm{Ca}^{2+}$.

Increasing the intraluminal $\mathrm{Ca}^{2+}$ concentration fourfold to $10.56 \mathrm{~mm}$ had no effect on the reabsorption of $\mathrm{Na}^{+}, \mathrm{Cl}^{-}$and water and secretion of $\mathrm{K}^{+}$(Table 3).

\section{Effect of amiloride and TAP}

The effect of amiloride is shown in Table 4. Amiloride $\left(10^{-4} \mathrm{M}\right)$ added to the intraluminal fluid produced a slight but insignificant inhibition of the transport of electrolytes and water across the isolated rat cauda epididymidis.

TAP produced a dose-dependent inhibition of the transport of electrolytes and water across the isolated rat cauda epididymidis (Table 5). At a concentration of $10^{-3} \mathrm{M}$ and when applied to both sides of the epithelium, it inhibited isosmotic water transport by about $60 \%$. The secretion of $\mathrm{K}^{+}$was not affected. When the concentration of TAP was increased to $10^{-2} \mathrm{M}$, inhibition of isosmotic 


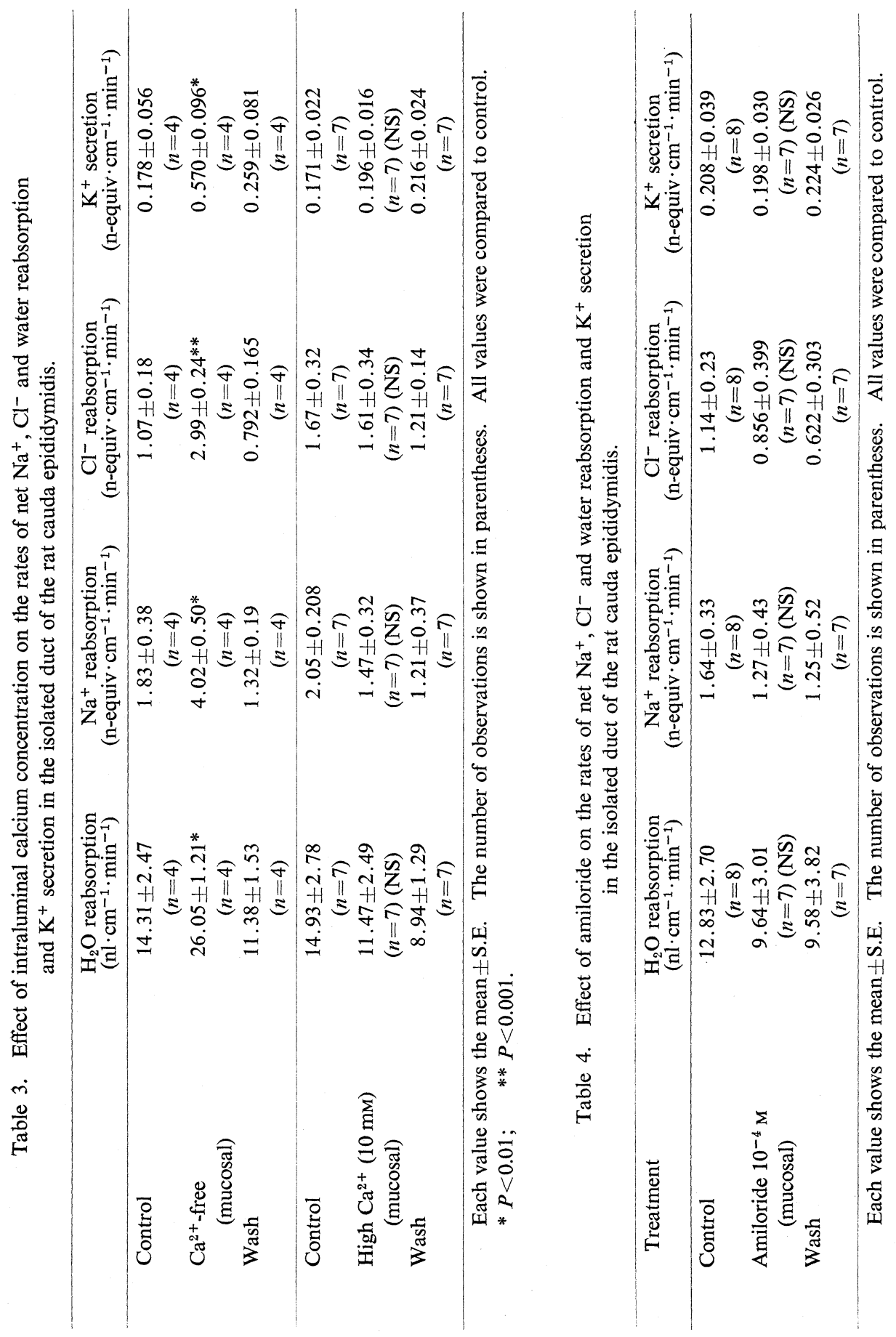




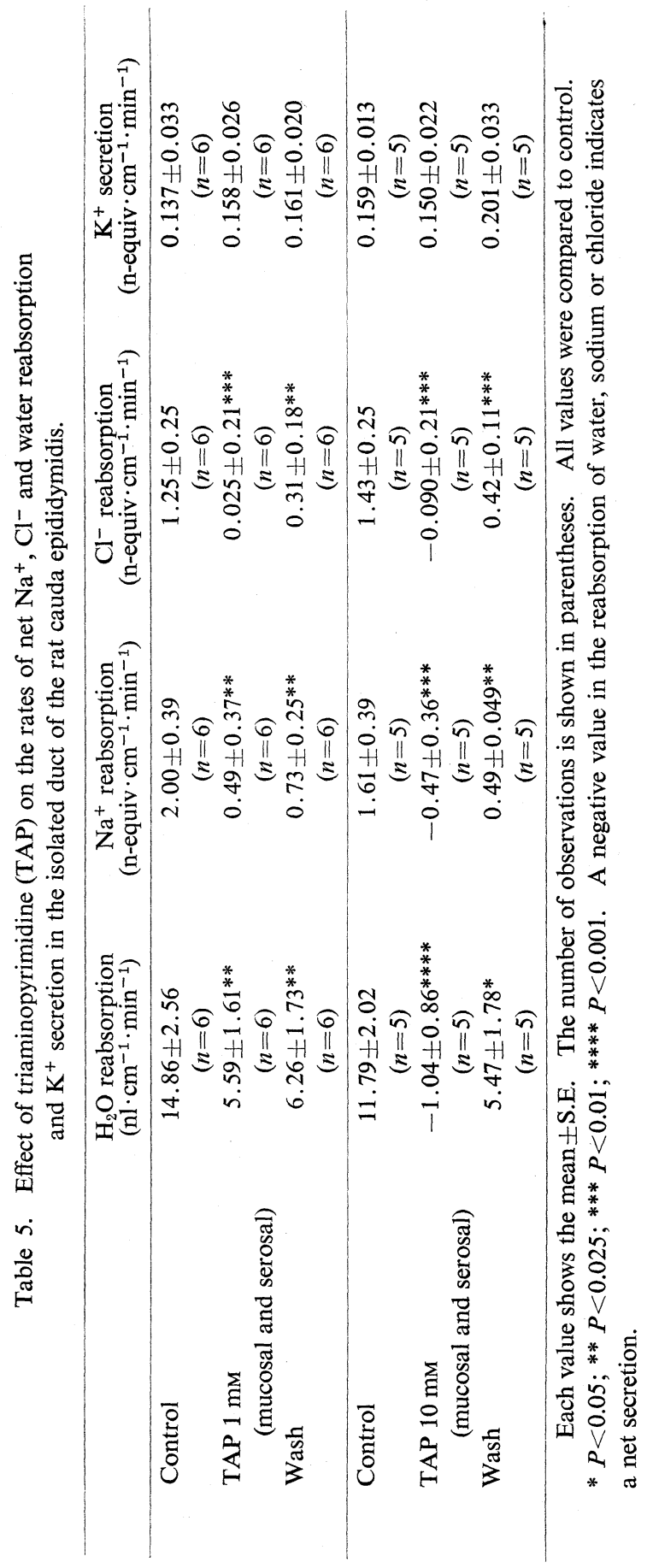




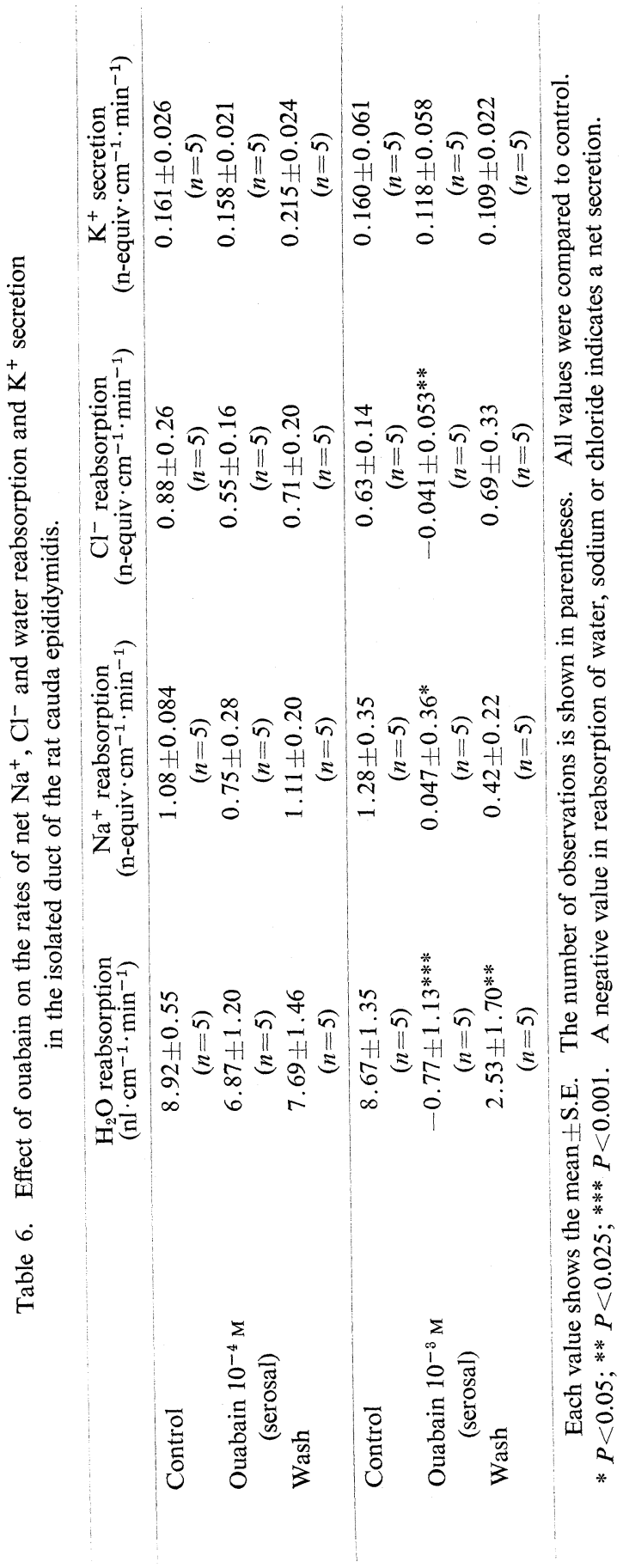




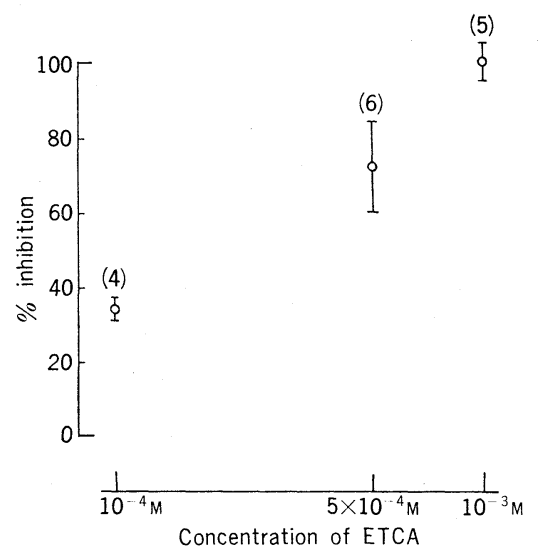

Fig. 4. Log-dose-response curve for the effect of ETCA on net fluid reabsorption in the isolated duct of the rat cauda epididymidis. ETCA was applied to the intraluminal perfusion solution only. Each point shows the mean \pm S.E. with the number of observations shown in parentheses.

water transport was complete and the effect was partially reversible upon washing out the drug. When TAP $\left(10^{-2} \mathrm{M}\right)$ was added to the luminal side only, the isosmotic water reabsorption was reduced from the control value of $12.67 \pm 1.16$ $\mathrm{nl} \cdot \mathrm{cm}^{-1} \cdot \mathrm{min}^{-1}$ (mean \pm S.E., $\left.n=3\right)$ to $7.07 \pm 2.82 \mathrm{nl} \cdot \mathrm{cm}^{-1} \cdot \mathrm{min}^{-1}($ mean \pm S.E., $n=3)$ ( $44 \%$ inhibition). Peritubular application of TAP $\left(10^{-2} \mathrm{M}\right)$ reduced the isosmotic water reabsorption from $13.50 \pm 1.46 \mathrm{nl} \cdot \mathrm{cm}^{-1} \cdot \mathrm{min}^{-1}$ (mean \pm S.E., $n=3$ ) to $9.53 \pm 2.40 \mathrm{nl} \cdot \mathrm{cm}^{-1} \cdot \mathrm{min}^{-1}$ (mean \pm S.E., $\left.n=3\right)(30 \%$ inhibition).

\section{Effect of ouabain and ETCA}

Two doses of ouabain were applied to the peritubular medium. The results are shown in Table 6 . At $10^{-4} \mathrm{M}$, ouabain inhibited isosmotic water reabsorption by about $25 \%$ (the results are not significantly different from the control) without affecting the $\mathrm{K}^{+}$secretion rate. When the dose was increased to $10^{-3} \mathrm{M}$, complete inhibition of isosmotic water reabsorption was achieved, and the $\mathrm{K}^{+}$secretion rate was reduced. The inhibition by ouabain was found to be only partially reversible upon washing out the inhibitor.

ETCA added to the intraluminal side at concentrations of $10^{-4} \mathrm{M}, 5 \times 10^{-4} \mathrm{M}$ and $10^{-3} \mathrm{M}$ was found to produce a dose-dependent but irreversible inhibition of sodium and water reabsorption. Only the log-dose-response curve on the isosmotic water reabsorption is shown (Fig. 4). Fifty percent inhibition was achieved at a concentration of about $2 \times 10^{-4} \mathrm{M}$.

\section{DISCUSSION}

This study reveals that transport of electrolytes and water across the isolated 
duct of the rat cauda epididymidis occurs at rates comparable to that in the intact epididymis in vivo (WoNG and YeUnG, 1978). Sodium chloride is reabsorbed isotonically with water and potassium is secreted into the ductal lumen. The isolated rat epididymal duct can therefore be used as a model for studying transport processes in the epididymis.

The transepithelial potential is negligible, with a value of $0.25 \pm 0.19 \mathrm{mV}$ with the lumen negative with respect to the outside. This indicates that the characteristic of the epididymal epithelium may conform to the leaky type, such as the renal proximal tubule and the gall bladder. This contention is further supported by experiments with amiloride and triaminopyrimidine (TAP). Amiloride has been shown to inhibit sodium transport in tight epithelia, e.g., the renal distal tubule (Guignard and Peters, 1970) and frog skin (Salako and Smith, 1970) and the action of TAP is confined to leaky epithelia, e.g., the gall bladder and choroid plexus (MORENO, 1975). In contrast to our in vivo experiments (WoNG and YEUNG, 1978), amiloride $\left(10^{-4} \mathrm{M}\right)$ was found to produce a slight but insignificant inhibition of $\mathrm{Na}^{+}$and water transport in the isolated cauda epididymal duct, whereas TAP (1 to $10 \mathrm{~mm}$ ) inhibited or completely abolished isosmotic water reabsorption when added to both sides or to the intraluminal side of the epithelium. The effect was greatest when added to both sides (Table 5). Since TAP has been shown to be a blocker of paracellular sodium channels in leaky epithelia (MORENO, 1975; BowmAN et al., 1978), this may suggest that sodium transport in the isolated duct of the rat cauda epididymidis is carried out through the low resistance paracellular pathway. Recently, a low input resistance across the epididymal duct has been recorded and this lends further support to this contention (Wong and $\mathrm{Au}$, unpublished).

Ouabain $\left(10^{-4} \mathrm{M}\right)$ slightly inhibited the rates of $\mathrm{Na}^{+}, \mathrm{Cl}^{-}$and water reabsorption and $\mathrm{K}^{+}$secretion in the rat cauda epididymidis although the results are not statistically significant. Complete inhibition was produced at $10^{-3} \mathrm{M}$. These effects were observed when ouabain was added to the peritubular side. ETCA, on the other hand, inhibited water and salt absorption when added to the luminal side. These results can be interpreted in the light of the recent suggestion that in epithelia there are two pumps, one located in the baso-lateral membranes involved in isosmotic $\mathrm{Na}^{+}$reabsorption, sensitive to ETCA; the other, located in the basal membranes, is involved in the regulation of cell volume and is ouabain sensitive. The action of ECTA, however, can also be due to factors other than the inhibition of the isosmotic pump since ECTA has been found to possess other pharmacological effects including inhibition of the membrane SH groups (CAFRUNY et al., 1974). Nevertheless, the present investigation confirms results from other isosmotic transporting epithelia in showing that net fluid transport by the rat cauda epididymis can be inhibited by the mucosal application of ETCA. The requirement of a high concentration of ouabain applied from the peritubular side in order to abolish cauda epididymis net fluid transport is also in agreement with 
previous observations in the gall bladder epithelium (FREDERIKSEN, 1978). Ouabain may influence fluid transport indirectly by inhibiting the $\mathrm{Na}^{+}-\mathrm{K}^{+}$pump which is required to maintain a low cellular $\mathrm{Na}^{+}$concentration and high $\mathrm{K}^{+}$concentration. A low intracellular $\mathrm{Na}^{+} / \mathrm{K}^{+}$ratio has been suggested to be a prerequisite for the optimal function of a transepithelial transport process (FREDERIKSEN and LEYSSAC, 1969).

Removal of $\mathrm{Ca}^{2+}$ from the intraluminal medium resulted in a twofold increase in isosmotic water reabsorption. The isolated rat cauda epididymidis therefore behaves similarly to the other $\mathrm{Na}^{+}$transporting epithelia in that mucosal $\mathrm{Ca}^{2+}$ regulates $\mathrm{Na}^{+}$transport (CURRAN and GILL, 1961; ANDERSON and ToMLINSON, 1965; Cuthbert and Wong, 1971, 1972). In the absence of intraluminal $\mathrm{Ca}^{2+}$ ions, $\mathrm{K}^{+}$secretion was also enhanced. This may be secondary to an increased $\mathrm{Na}^{+}$reabsorption in the epididymal duct.

When $\mathrm{K}^{+}$was removed from the peritubular fluid, no effect on $\mathrm{Na}^{+}$and water reabsorption was observed. $\mathrm{Cl}^{-}$absorption was however increased. Since peritubular $\mathrm{K}^{+}$was not required for isosmotic water transfer in the isolated rat cauda epididymidis, it can be inferred that the $\mathrm{Na}^{+}-\mathrm{K}^{+}$pump located in the basal membrane may not be involved in isosmotic water reabsorption (see above). In this context, $\mathrm{Na}^{+}$reabsorption in the cauda epididymidis may be different from that of tight epithelia, e.g., in frog skin, in which serosal $\mathrm{K}^{+}$is required for net transepithelial $\mathrm{Na}^{+}$transport. Secretion of $\mathrm{K}^{+}$was completely abolished when $\mathrm{K}^{+}$was omitted from the peritubular medium. One possible explanation is that $\mathrm{K}^{+}$ secretion is derived not from the intracellular store but from the peritubular medium. A similar effect of extracellular $\mathrm{K}^{+}$on $\mathrm{K}^{+}$secretion in the isolated rat seminiferous tubules has also been demonstrated (CHEUng et al., 1977). It is possible that a decrease in intracellular $\mathrm{K}^{+}$concentration due to cessation of the $\mathrm{Na}^{+}-\mathrm{K}^{+}$pump exerts an inhibitory effect on the secretary $\mathrm{K}^{+}$movement across the luminal membrane. The increase in $\mathrm{Cl}^{-}$reabsorption seen in the absence of peritubular $\mathrm{K}^{+}$ions may be caused by an increase in the electrical potential difference generated by $\mathrm{Na}^{+}$reabsorption in the absence $\mathrm{K}^{+}$secretion. The process of $\mathrm{Na}^{+}$reabsorption coupled to $\mathrm{Cl}^{-}$reabsorption or $\mathrm{K}^{+}$secretion in the rat cauda epididymidis may be very similar to that in the distal tubule of the kidney (MALNIC et al., 1966; WrIGHT, 1977).

The isosmotic fluid reabsorption in the rat cauda epididymis is very sensitive to temperature as is shown in Table 2 . Lowering the temperature to $25^{\circ} \mathrm{C}$ suppressed isosmotic water transport and potassium secretion as expected for active processes. Raising it to the body temperature of $38^{\circ} \mathrm{C}$ however had no effect. BEDFORD (1978) has recently provided evidence that in the rat if the cauda epididymidis is transposed to the abdomen, the storage function of the cauda is disrupted without affecting the maturation processes of the spermatozoa; presumably sperm maturation is carried out at the caput and initial corpus epididymidis. In the light of these results, WoNG et al. (1979), studied electrolyte and water 
transport in the cauda epididymidis of anesthetized rats in vivo and found that body temperature adversely affected these transport processes. Our present experiments, however, did not reveal an acute effect of body temperature on isosmotic water reabsorption in the isolated duct in vitro. It seems that body temperature may require some time to deactivate the transport mechanism. In the in vivo study, reabsorption of $\mathrm{Na}^{+}$and water was inhibited by about $50 \%$ after transposing the cauda epididymidis to the abdomen for four days (Wong et al., 1979). Since the epithelial activities of the epididymis are recognized as being critical for sperm maturation and surival (see WoNG, P.Y.D. et al., 1978), it is important to understand the mechanisms of transport processes in the epididymis.

This work was supported by a grant from the World Health Organization. We are grateful to Dr. Barbara Roth for the synthesis of triaminopyrimidine, and to Merck, Sharp \& Dohme for the gifts of amiloride and ethacrynic acid.

\section{REFERENCES}

Anderson, J. and Tomlinson, R. W. S. (1965) The effect of high and low concentrations of calcium on sodium transport by the isolated toad bladder. J. Physiol. (Lond.), 177: 133-139.

Au, C. L., NGaI, H. K., Yeung, C. H., and Wong, P. Y. D. (1978) Effect of adrenalectomy and hormone replacement on sodium and water transport in the perfused rat cauda epididymidis. J. Endocrinol., 77 : 265-266.

BEDFORD, J. M. (1978) Influence of abdominal temperature on epididymal function in the rat and rabbit. Am. J. Anat., 152: 509-522.

Bowman, R. H., ARnow, J., and WeIner, I. M. (1978) The effects of 2,4,6-triaminopyrimidine (TAP) on sodium and potassium excretion by the rat kidney: Comparison with amiloride. J. Pharmacol. Exp. Ther., 206: 207-217.

Cafruny, E. J., Koechel, D. A., and Nigrovic, V. (1974) Receptors for mercurial and ethacrynic acid inhibition of sodium and chloride transport. In: Drugs and Transport Processes, ed. by Callingham, B. A. Macmillan, London, pp. 23-36.

Cheung, Y. M., Hwang, J. C., and Wong, P. Y. D. (1977) In vitro measurement of rate of fluid secretion in rat isolated seminiferous tubules: Effects of metabolic inhibitors and ions. J. Physiol. (Lond.), 269: 1-15.

Curran, P. F. and Gill, J. R. (1961) The effect of calcium on sodium transport in frog skin. J. Gen. Physiol., 45: 625-641.

Cuthbert, A. W. and Wong, P. Y. D. (1971) The effect of metal ions and antidiuretic hormone on oxygen consumption in toad bladder. J. Physiol. (Lond.), 219: 39-56.

Cuthbert, A. W. and Wong, P. Y.D. (1972) The role of calcium ions in the interaction of amiloride with membrane receptors. Mol. Pharmacol., 8: 222-229.

DiAmond, J. M. (1968) Transport mechanisms in the gall-bladder. In: Handbook of Physiology, Sec. 6, ed. by CoDe, C. F. Williams \& Wilkins, Baltimore, pp. 2451-2482.

FREDERIKSEN, O. (1978) Functional distinction between two transport mechanisms in rabbit gall-bladder epithelium by use of ouabain, ethacrynic acid and metabolic inhibitors. $J$. Physiol. (Lond.), 280: 373-387.

Frederiksen, O. and Leyssac, P. P. (1969) Transcellular transport of isosmotic volumes by the rabbit gall-bladder in vitro. J. Physiol. (Lond.), 201: 201-224.

Giebisch, G., Sullivan, L. P., and Whittembury, G. (1973) Relationship between tubular net sodium reabsorption and peritubular potassium uptake in the perfused necturus kidney. 
J. Physiol. (Lond.), 230 : 51-74.

Guignard, J. P. and Peters, G. (1970) Effects of triameterene and amiloride on urinary acidification and potassium excretion in the rat. Eur. J. Pharmacol., 10: 255-267.

Kleinzeller, A. (1961) The role of potassium and calcium in the regulation of metabolism in kidney cortex slices. In: Membrane Transport and Metabolism, ed. by KLEINZELLeR, A. and Kотук, A. Academic Press, London and New York, pp. 527-542.

Malnic, G. R., Klose, M., and Giebisch, G. (1966) Micropuncture study of distal tubular potassium and sodium transfer in rat nephron. Am. J. Physiol., 211: 259-547.

Moreno, J. H. (1975) Blockade of gallbladder tight junction, cation-selective channels by 2,4,6-triamino-pyridinium (TAP). J. Gen. Physiol., 66: 97-116.

Salako, L. A. and Smith, A. J. (1970) Effects of amiloride on active sodium transport by the isolated frog skin: Evidence concerning site of action. Br. J. Pharmacol., 38: 702-718.

Whittembury, G. (1968) Sodium and water transport in kidney proximal tubular cells. J. Gen. Physiol., 51: 303-314.

Wong, P. Y. D. and Yeung, C. H. (1977) Hormonal regulation of fluid reabsorption in isolated rat cauda epididymidis. Endocrinology, 101: 1391-1397.

Wong, P. Y. D. and Yeung, C. H. (1978) Absorptive and secretory functions of the perfused rat cauda epididymidis. J. Physiol. (Lond.), 275: 13-26.

Wong, P. Y. D., AU, C. L., and BedFord, J. M. (1979) A suppressive effect of body temperature on ion and water transport in the rat cauda epididymidis. Anat. Rec., in press.

Wong, P. Y. D., Au, C. L., and NGAI, H. K. (1978) Electrolyte and water transport in rat epididymis; its possible role in sperm maturation. Int. J. Andro. (Suppl.), 2: 608-628.

Wong, Y. C., Wong, P. Y. D., and Yeung, C. H. (1978) Ultrastructural correlation of water reabsorption in isolated rat cauda epididymidis. Experientia, 34: 485-487.

WRIGHT, F.S. (1977) Sites and mechanisms of potassium transport along the renal tubule. Kidney Int., 11 : 415-432. 